\title{
MODEL INTEGRATION (BIM) FOR MAINTENANCE BUILDING AS INFORMATION AND ACTION PLAN IN LAUNDRY LABORATORY AND KITCHEN LABORATORY OF PETRA SURABAYA CHRISTIAN UNIVERSITY
}

\author{
Ary Sunantiyo \\ Faculty of Engineering \\ Civil Engineering Study Program \\ Narotama University Surabaya \\ ary.sunantiyo@gmail.com \\ Ronny Durrotun Nasihien \\ Faculty of Engineering \\ Civil Engineering Study Program \\ Narotama University Surabaya \\ ronny.durrotun@narotama.ac.id
}

\begin{abstract}
Maintenance of each building along with every component and its facilities is needed to provide smooth and comfortable activities in the building. Often the building maintenance process/activity has not been able to run properly due to a lot of information such as maintenance records, work drawings (as-built drawings), types of assets, specifications, repair, and maintenance history that have not been recorded or stored properly. Most building maintenance systems currently only focus on existing information or records. The proposed information system is to utilize 3D modeling techniques namely BIM (Building Information Modeling), which through this BIM will be able to capture relevant information according to the data in the building. The technology used is the BIM (Building Information Modeling) technology using the SketchUp program. This method is by making a model of the building and its facilities. Modeling is done by giving visual data in 3D (three dimensions) to resemble the original object. The benefit of 3D (three-dimensional) modeling is that it provides clearer information because the visualization displayed is the same as the original object at the location, so just looking at the 3D model is quite the same as seeing the original object at the location. This research resulted in an information system in the form of three-dimensional visual model images that can be accessed easily. This concludes that an integrated Building Information Modeling (BIM) based system can provide useful functions in building maintenance quickly and accurately.
\end{abstract}

Keywords: BIM, Maintenance management, buildings, building assets, building facilities, information systems, SketchUp

\section{INTRODUCTION}

All existing buildings will always be endeavored to be used in conditions that are safe, comfortable and durable. Over time, the condition of a building will experience a phase of decreased quality, so it is necessary to carry out regular maintenance/maintenance. Building maintenance should be carried out routinely or periodically, especially in supporting facilities such as mechanical, electrical, internet, telephone, air conditioning, and other facilities.

Another thing that needs to be a concern also is databases such as asset type data, building specifications, repair, and maintenance history, and all repair data needs to be updated and stored properly. With a good information system, it will be very helpful for maintenance management to perform maintenance on a building better. At this time, 3D visualization technology has become one of the things that can be used in supporting maintenance management tasks. Applications that can be used to do 3D modeling include SketchUp.

The object of this research is:

1. Exploring 3D Modeling (3 Dimensions) as an information system that can provide good and directed visualization 
2. "Sketchup" can describe and show the results of integration in the form of 3D images (3 Dimensions) on objects/components in a building/building well and clearly.

3. The information provided to the maintenance management section will be easily $\mathrm{read} / \mathrm{understood}$, so that in carrying out its duties the data can be given in full, fast and directed.

The benefits of this research are expected to provide benefits about the general picture that can be applied to make effective and efficient maintenance of buildings in one building using a 3-dimensional (3D) information system commonly referred to as Building Information Modeling.

\section{LITERATURE REVIEW}

\section{PREVIOUS RESEARCH}

Some previous studies which in this case became one of the references of the author is researching so that the author can enrich the theory used to study the research conducted, including the following:

Table 1. The Building Information Model in Facilities Management

\begin{tabular}{|c|l|l|l|}
\hline No & \multicolumn{1}{|c|}{ Title } & \multicolumn{1}{c|}{ Researcher } & \multicolumn{1}{c|}{ Conclusion } \\
\hline 1 & $\begin{array}{l}\text { The Building } \\
\text { Information Model }\end{array}$ & $\begin{array}{l}\text { Ronald O. Méndez A } \\
\text { Thesis Submitted to } \\
\text { in Facilities } \\
\text { Management }\end{array}$ & $\begin{array}{l}\text { The use of BIM and information } \\
\text { the Fachulty of the } \\
\text { WORCESTER } \\
\text { POLYTECHNIC } \\
\text { change the face of the construction } \\
\text { industry. This technology is used to } \\
\text { overcome communication gaps } \\
\text { INSTIUTE ), May } \\
\text { between planners, contractors, } \\
\text { dealers/vendors, owners, and } \\
\text { operators. }\end{array}$ \\
\hline
\end{tabular}

Table 2. Bim - Based Knowledge Management for Building Maintenance

\begin{tabular}{|c|l|l|l|}
\hline No & \multicolumn{1}{|c|}{ Title } & \multicolumn{1}{|c|}{ Researcher } & \multicolumn{1}{c|}{ Conclusion } \\
\hline 1 & Bim - Based & Abdul Kareem & Utilizing BIM technology to support \\
& Knowledge & Almarshad, MSc. & Facility Management and Building \\
& Management for & School of the Built & Maintenance activities. \\
& Building & Environment, Heriot- & \\
& Maintenance & Watt University, & \\
& & Edinburgh, UK, & \\
& & Ibrahim Motawa, & \\
& & Ph.D. October 2012 & \\
\hline
\end{tabular}

Table 3. Integration of Building Maintenance Data in the Application of Building Information Modeling (BIM)

\begin{tabular}{|c|l|l|l|}
\hline No & \multicolumn{1}{|c|}{ Title } & \multicolumn{1}{|c|}{ Researcher } & \multicolumn{1}{c|}{ Conclusion } \\
\hline 1 & Integration of & Dooyong Ahn, & Facility maintenance work is carried \\
& Building & Heesung Cha, & out using a BIM model-based \\
& Maintenance & Department of & process, the building maintenance \\
& Data & Architectural & process will be stronger and more \\
& in the Application & Engineering, Ajou & efficient at each sub-process stage. \\
& of Building & University, Suwon, & \\
& Information & South Korea. June & \\
& Modeling (BIM) & 2014 & \\
\hline
\end{tabular}


Maintenance management of a building is often overlooked because its effects are not felt directly (Mandagi et al., 2017).

Management is defined as efforts and activities to achieve a goal by using human resources and other resources effectively and efficiently. Effective means that the planned goals and objectives can be achieved as expected, whereas efficient means achieving optimal results with minimal effort.

Maintenance (Regulation of the Minister of Public Works, 2008) is defined as an activity to repair and/or replace parts of a building, components, building materials, and/or building infrastructure and facilities to maintain proper function.

Maintenance (Minister of Public Works Regulation, 2008) is an effort to maintain the condition of the building so that it continues to function as it should or to improve the function of the building and guard against any damage that occurs

\section{Maintenance Achievements Using BIM}

The existence of Building Information Modeling Technology (BIM) as a Tool (Liu \& Issa, 2014) is expected to be able to bridge between one work activity with other work activities so that the friction that occurs can be prevented/reduced. youtube link (Designs, 2014)

\section{Definition of Building Information Modeling (BIM)}

The basic understanding of BIM is the collaboration of many different stakeholders at different phases of the life cycle of facilities to enter, delete, update or modify information in BIM to support and reflect the roles of various stakeholders.

Based on some of the definitions mentioned above, it can be concluded that BIM (Abdullah et al., 2014) is not only a technology but also includes a process using products from the right software. youtube link (TV, 2015)

\section{Integration of Building Information Modeling (BIM) with Maintenance Management}

In the current era of modern technology, BIM can be used to map the level of functionality of a building and its assets. However, to implement the use of BIM in maintenance (Arayici et al., 2012), several things must be emphasized and handled, according to the BIM Implementation

1. We need to consider how this digital information can be integrated for maintenance management.

2. Need to consider an inventory of all available equipment, this will make it easy to access information either regularly or suddenly if there is damage.

The successful implementation of BIM will depend on the software used, the number of people who will use this BIM technology, the type of information that can be shared and many others. It cannot be denied that BIM offers a higher standard of functionality for the maintenance of a building as an integrated digital system for every component in a building/building. youtube link (Tooley, 2013) 
Flow Chart

\section{RESEARCH METHODOLOGY}

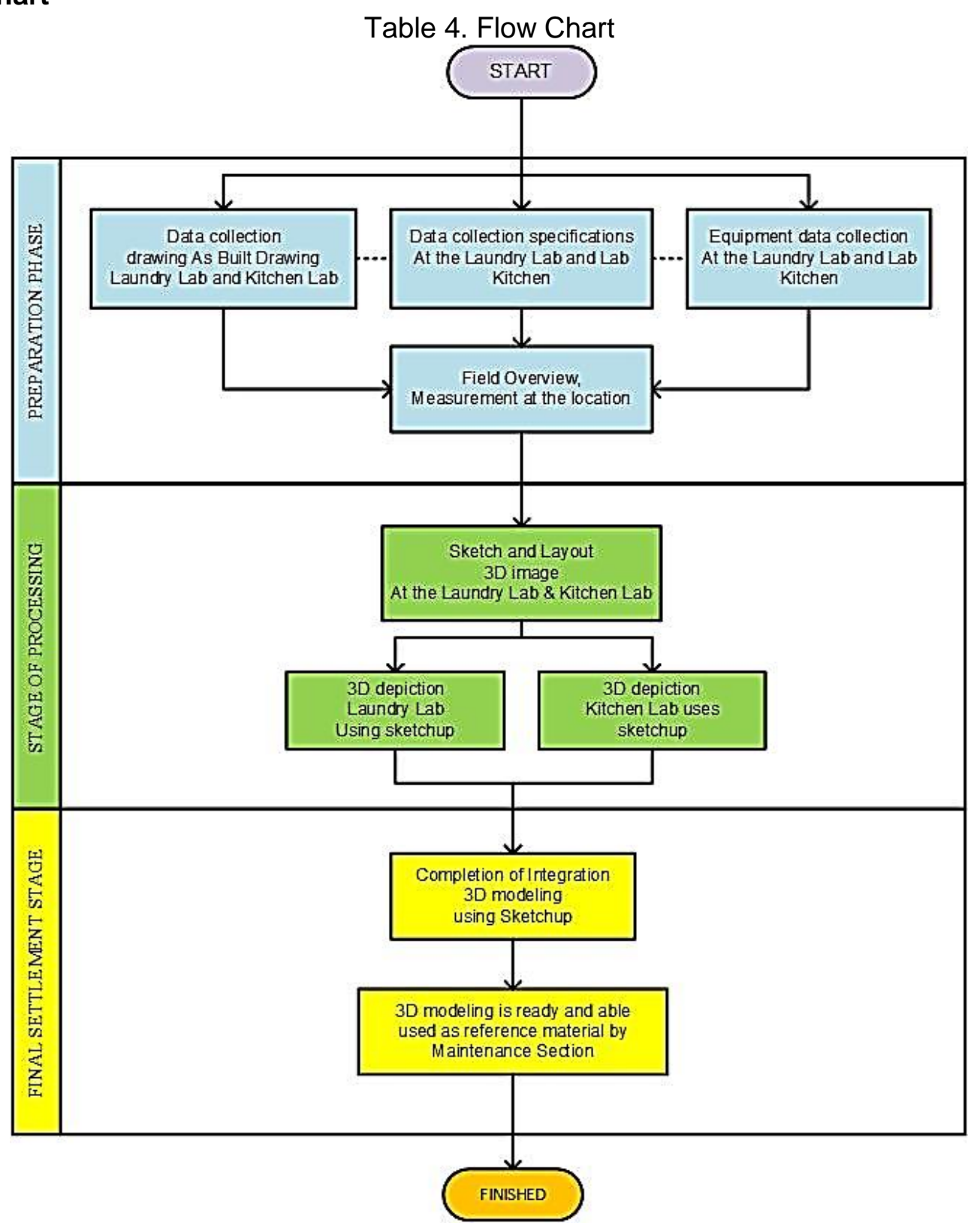

\section{Preparation Phase}

In this stage, the works include Collection of As-Built Drawing both in hard copy and soft copy, Collection of Specifications data for all materials used, Collection of data for tools used. the next step is to conduct a site inspection and to collect data and measurements at the location to ensure that all those in the location are by the as-built drawings and available inventory data.

\section{Processing Phase}

Make sketches and drawings to be a guide in drawing 3D (3 Dimensions), After getting a picture for a picture on location then the next step is to do a 3D depiction using the software "Sketchup"

\section{Final Settlement Stage}

Integrating 3D modeling for all objects that have been drawn using SketchUp into one integrase, and processing the $3 \mathrm{D}$ modeling into an information system that can be used 
as a reference for the building maintenance management unit / Maintenance Building in carrying out maintenance tasks.

\section{Discussion}

\section{RESULTS AND DISCUSSION}

With some of the background above, the authors try to provide several alternatives in solving these problems, including by making 3D images (three dimensions) that are easily understood and understood by the executors in the field in carrying out the maintenance and care of all installations in each Existing Laboratory.

\section{Preparation Phase}

a. As-Built Drawing data collection, namely searching and collecting as-built drawings, both architectural, structural, mechanical, electrical and other work stored in the Campus Physical Planning Unit (UPFK).

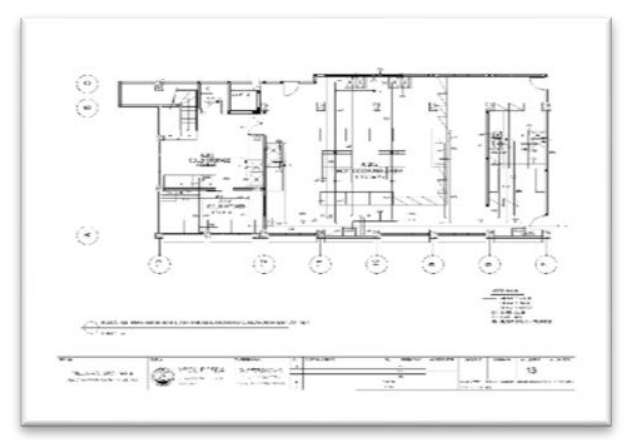

Figure 1. Image of Digitizing CAD

b. Building Specifications data collection by looking for Work Plan documents and conditions used when the building was built/renovated.

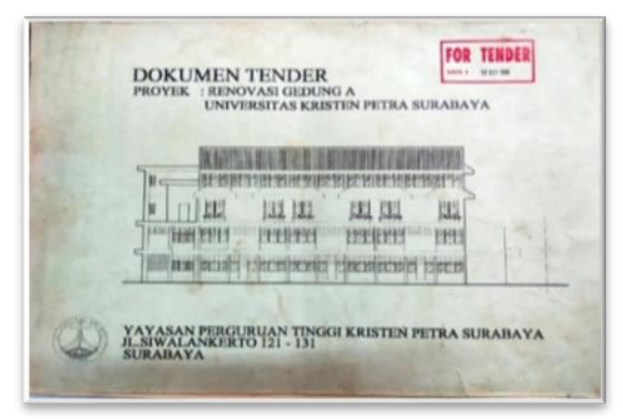

Figure 2. Building Specifications Data Document

c. Data collection of equipment used and review to each laboratory and interviews with staff in each laboratory to ensure all equipment used.

d. Site reviews and measurements, as well as field measurements to obtain and ensure that all data that has been obtained is by the conditions on the ground

\section{Processing Phase}

After the data collection process is done then the next process is the Model Making Process, following several stages of 3D Modeling processing 

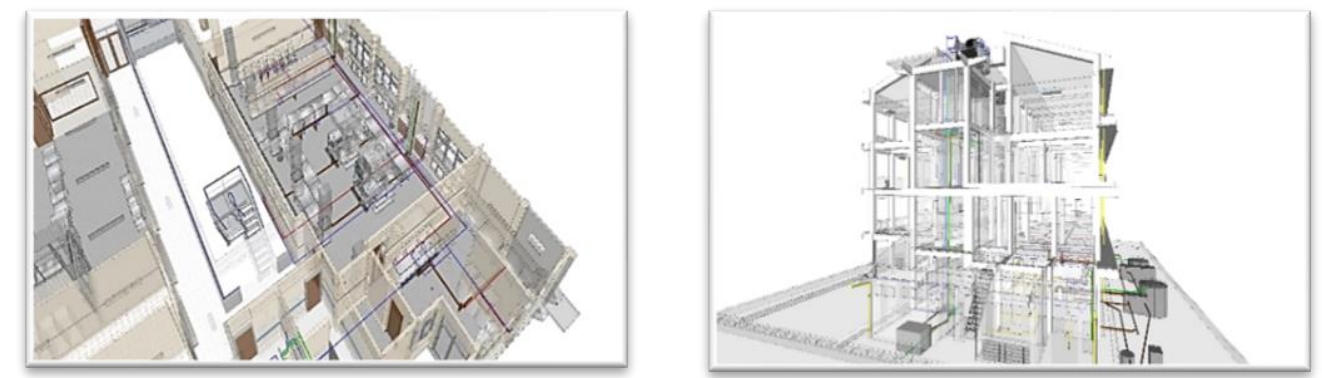

Figure 3. Sketchup modeling

\section{Final Settlement Stage}

What is being done is the Processing of Modeling into a good integration between Structural Modeling, Architecture, Mechanical, Electrical, and others, along with some of the results of the Integration of Modeling.
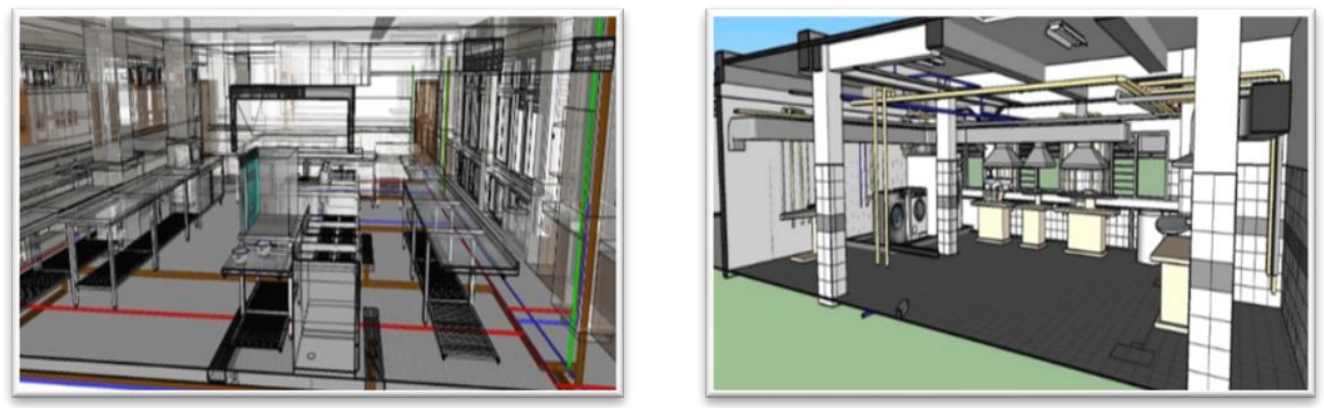

Figure 4. Integration in the Kitchen and Laundry Laboratory

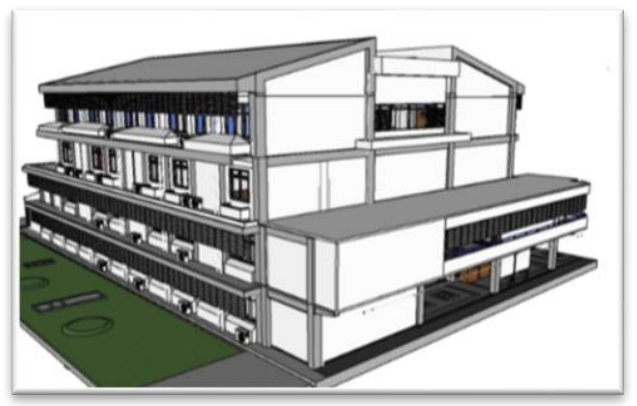

Figure 5. Building Model Results

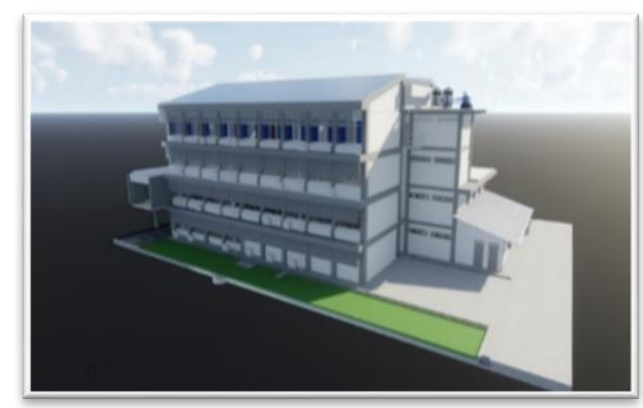

Figure 6. Building Model that has been rendered

\section{Conclusions}

\section{CONCLUSIONS}

1. 3D Modeling Results (3 Dimensions) that have been produced in general can be used as information that can provide a visualization of a building well and directed.

2. Software "Sketchup" as one of the tools used in 3D modeling (three dimensions) in general can describe and show the results of 3D integration (three dimensions) on objects/components in a building/building clearly,

3. 3D Modeling Information System that can be given to the Maintenance Management including among others in the form of images such as floor plans, looks, pieces, details, etc., which are the result of processing 3D images that have been integrated and are expected to be easily read/understood as a reference in the process of work/maintenance activities.

\section{Suggestions}


to improve and support the results of 3D modeling (three dimensions) produced by Sketchup include:

1. Modeling results produced by Sketchup can be reprocessed by using additional extensions including by using:

a. BIM Up, the purpose of this BIM UP Extension is to calculate the volume, dimensions, and quantity as well as the data needs of a building such as landscape, feasibility studies, and others, following the link from BIM Up, http://www.bimup.co.uk/ (BIM UP, nd)

b. PLUSSPEC, The use of this Extension is for Design \& Drafting, Estimating \& Construction, Spesification (Building Products), here is a link from Plus spec: https://plusspec.com/ (Ruby Sketch, n.d.)

2. To produce smoother and better rendering images, you can use the Extension with the name ESCAPE, following the link from Enscape, https://enscape3d.com/(Enscape, n.d.)

All of these extensions have been linked to Sketchup so that it is easy to use and can improve the results of modeling produced by Sketchup to be implemented in Building Information Modeling that is more complete and integrated

\section{REFERENCES}

[1] Abdullah, S., Sulaiman, N., Latiffi, A., \& Baldry, D. (2014). Building Information Modeling (BIM) from the perspective of Facilities Management (FM) in Malaysia. International Real Estate Research Symposium, (April), Unpublished. https://doi.org/10.13140/2.1.4886.0164

[2] Arayici, Y., Onyenobi, T., \& Egbu, C. (2012). Building Information Modeling (BIM) for Facilities Management (FM). International Journal of 3-D Information Modeling, 1 (1), 55-73. https://doi.org/10.4018/ij3dim.2012010104

[3] BIM UP. (n.d.). BIM UP. Taken from http://www.bimup.co.uk/

[4] Designs, B. (2014). Sketchup is BIM. Taken April 18, 2019, from https://www.youtube.com/watch?v=3ZvouCvfUMA

[5] Enscape. (n.d.). ESCAPE. Taken from https://enscape3d.com/

[6] Liu, R., \& Issa, R. R. A. (2014). Design for maintenance of accessibility using BIM tools. Facilities. https://doi.org/10.1108/F-09-2011-0078

[7] Mandagi, A., Kawatu, P. A. T., Malonda, N. S. H., Society, F. K., \& Ratulangi, U. S. (2017). The Relationship between Knowledge and Attitudes with the Actions of Using Personal Protective Equipment on Construction Project Construction Workers at the Faculty of Public Health, Sam Ratulangi University, Manado. Journal of Health Media.

[8] Minister of Public Works Regulation. (2008). Guidelines for Building Maintenance and Maintenance. Guidelines for Building Maintenance and Maintenance. https://doi.org/S0161-6420(07)00634-3 [pii] \n10.1016 / j. ophtha.2007.06.001

[9] RubySketch. (n.d.). Plusspec. Taken from https://plusspec.com/

[10]Tooley, R. (2013). BIM TO FM INTEGRATION. Taken April 18, 2019, from https://www.youtube.com/watch?v=atuYq47HcD0

[11]TV, I. B. S. (2015). BIM FM. Taken April 18, 2019, from https://www.youtube.com/watch?v=cCe3SLLBgU0 